International Journal of Trend in Scientific Research and Development (IJTSRD)

Volume: 3 | Issue: 2 | Jan-Feb 2019 Available Online: www.ijtsrd.com e-ISSN: 2456 - 6470

\title{
Immunoauppresive Drugs for Renal Transplantation
}

\author{
Neha Sharma \\ B.SC Dialysis Technology, Pt. J.N.M.Medical College, Raipur, Chhattisgarh, India
}

\begin{abstract}
For most patients with chronic kidney failure, kidney transplantation has the greatest potential for restoring a healthy and productive life. The risk of acute rejection is the highest in the first months after transplantation (induction phase) and diminishes afterwards (maintenance phase).

Immunosuppression should be at the highest level in the early period and reduced for long-term therapy. At present, conventional immunosuppressive protocols consist of the triple therapy: a calcineurin inhibitor, an adjunctive agent, corticosteroids. The development of new immunosuppressives drugs is aimed not only at improving short-term outcomes, but also achieving better safety, less nephrotoxicity and minimal side effects. Suppression of allograft rejection is the central issue in renal transplantation (RT). Thus, development of immunosuppressive agents is the key for successful allograft function.

Immunosuppression agents in RT have evolved over the last six decades beginning with total lymphoid irradiation to the currently available immunosuppressive strategies, which have significantly reduced the incidence of acute rejection episodes and improved short-term graft and patient outcomes. However their use is associated with long-term graft dysfunction, hypertension, hyperlipidaemia, diabetes mellitus, infections and malignancies. Chronic antibody-mediated rejection and chronic allograft dysfunction still remain the major problems, often leading to graft loss and shortened long-term graft survival. Immunosuppressive agents are used for induction, maintenance and reversal of established rejection. The use of multidrug regimen tailored to the immunological risk of patient and adverse-effect profile of the drug provides the optimum outcomes. This review focuses on the evolution of immunosuppression agents used in RT over last six decades and highlights the newer agents under investigation.
\end{abstract}

Keywords: immunosuppresants, kidney transplantation, induction therapy, maintenance therapy, Calcineurin inhibitors (CNI): Cyclosporine (CsA) and Tacrolimus (Tac)

\section{INTRODUCTION}

Renal transplantation (RT) is the best modality of renal replacement therapy for most patients with stage- 5 chronic kidney disease, as this improves the quality of life, patient survival and is cost-effective

1. Since the first successful RT performed between the identical twins in the Peter Brent Brigham Hospital, Boston on 23rd December 1954 by Murray et al, RT has become a routine

2. According to the World Health Organisation, in 2013, a total of 78950 kidney transplants were performed in 104 countries worldwide.

3. When a kidney is transplanted from a human leucocyte antigen (HLA) non-identical donor, the recipient mounts an alloimmune response that leads to $\mathrm{T}$ lymphocyte activation, antibody production, complement activation, allograft rejection and transplant failure.

4. Immunosuppressive agents are used to prevent acute cellular and antibody-mediated rejections (AMR), both early and late, which lead to chronic allograft injury (CAI) in long-term. Significant advances have been made in the immunosuppressive strategies over the past three decades to reduce the incidence of allograft rejection and side-effects of the drugs, and to improve long-term graft and patient survivals. Introduction of cyclosporine revolutionised the practice of RT by reducing acute rejection rate and improved the short-term graft survival, which was further improved by tacrolimus, mycophenolate mofetil (MMF) and induction immunosuppressive agents. Despite these advances, there is lack of clear evidence of improvement of longterm graft survival because CAI continues to cause late renal allografts losses.

CLASSIFICATION OF IMMUNOSUPPRESSIVE THERAPY IMMUNOSUPPRESIVE DRUGS ARE CLASSIFIED INTO FOLLOWING CLASSES-

1. CALCINURIC INHIBITOR- cyclosporine, Tacrolimus

2. ANTIPROLIFERATIVE DRUGS- azathioprine, cyclophosphamide, mycophenolate mofetile

3. CORTICOSTEROIDES- prednisolsone,

4. MONOCLONAL AND POLYCLONAL ANTIBODIESantitymocyteglobuline , muromonab(CD3) , ATG 
International Journal of Trend in Scientific Research and Development (IJTSRD) @ www.ijtsrd.com eISSN: 2456-6470

Classification according to their clinical application-

\begin{tabular}{|l|l|l|}
\hline \multicolumn{1}{|c|}{ Inducting agent } & \multicolumn{1}{|c|}{ Maintenance agents } & \multicolumn{1}{c|}{ Rescue agents } \\
\hline $\begin{array}{l}\text { Polyclonal and monoclonal } \\
\text { antibodies: ATG OKT3 }\end{array}$ & $\begin{array}{l}\text { Calcineurin inhibitors: Cyclosporine } \\
\text { Tacrolimus }\end{array}$ & $\begin{array}{l}\text { Mild to moderate cellular rejection: } \\
\text { Corticosteroids }\end{array}$ \\
\hline $\begin{array}{l}\text { Interleukin-2 receptor antagonists: } \\
\text { Basiliximab Daclizumab }\end{array}$ & $\begin{array}{l}\text { Anti-metabolites: Azathioprine } \\
\text { Mycophenolate mofetil }\end{array}$ & $\begin{array}{l}\text { Moderate to severe cellular } \\
\text { rejection: Polyclonal and } \\
\text { monoclonal antibodies: ATG OKT3 }\end{array}$ \\
\hline Methylprednisolone & $\begin{array}{l}\text { m-TOR inhibitors: Sirolimus } \\
\text { Everolimus }\end{array}$ & $\begin{array}{l}\text { Acute antibody-mediated rejection: } \\
\text { Immunoglobulins Rituximab } \\
\text { Bortezomib Eculizumab }\end{array}$ \\
\hline & $\begin{array}{l}\text { Newer agents: Co-stimulation blocker: } \\
\text { Belatacept Protein kinase C inhibitor: } \\
\text { Sotrastaurin JAK 3 inhibitor: Tofacitinib }\end{array}$ & \\
\hline
\end{tabular}

\section{MECHANISM OF ACTION OF IMMUNOSUPPRESSIVE DRUGS}

\section{THE THREE-SIGNAL MODEL}

The three-signal model of T-cell activation and subsequent cellular proliferation is a valuable tool for understanding the sites of action of the agents.

\section{IN BRIEF-}

$>\quad$ signal 1 is an antigen-specific signal provided by the triggering of the T-cell receptors by antigen-presenting cells (APCs) and is transduced through the CD3 complex.

$>$ Signal 2 is a non-antigen-specific co stimulatory signal provided by the engagement of B7 on the APC with CD28 on the T cell. These two signals activate the intracellular pathways that lead to the expression of interleukin-2 (IL-2) and other growth-promoting cytokines. Stimulation of the IL-2 receptor (CD25) leads to activation of mTOR (mammalian target of rapamycin) and provides signal 3, which triggers cell proliferation.

\section{Figure. Individual Immunosuppressive Drugs and Sites of Action in the 3-Signal Model'}

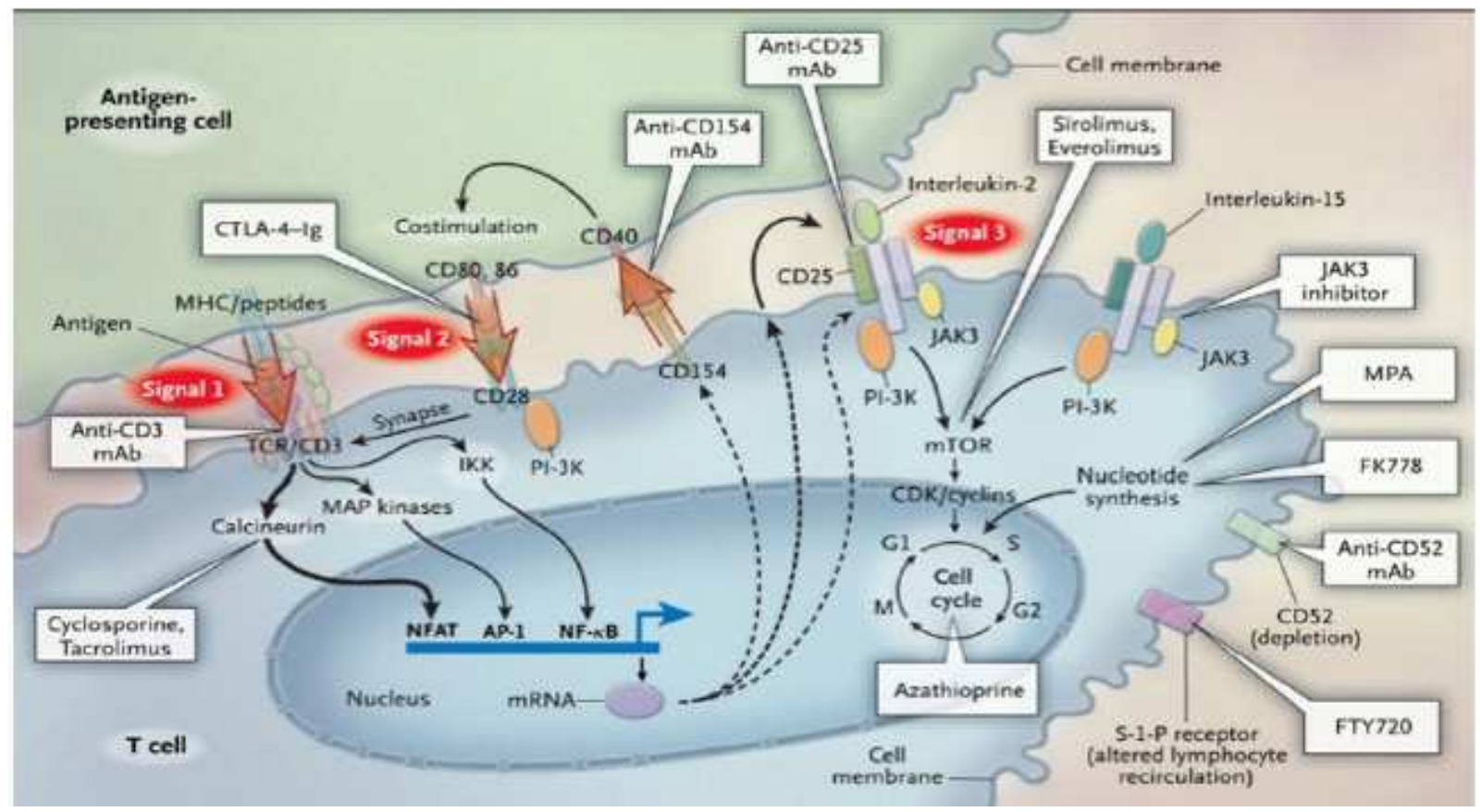

Immunosuppressive Agents in Renal Transplantation

\section{Total lymphoid irradiation}

$>$ Total lymphoid irradiation (TLI) has been the first method of immunosuppression in human RT based on the principle of the destruction of blood cells in bone marrow and lymphoid tissue responsible for rejection .

$>$ In a prospective randomised trial, which compared preoperative TLI with post-operative cyclosporine therapy, Waeret al. observed significantly high incidence of acute rejection rate in the TLI group, although the infectious complications were identical.
$>$ Zhu et al. successfully desensitised and rescued highly sensitised and RT recipients with AMR using a combination of TLI, low-dose IVIG and ATG and plasmapheresis. The side-effects of TLI, such as nausea, vomiting, diarrhoea, hair loss, bone marrow suppression and infections made this form of treatment less favourable.

$>$ It is more effective if given prior to transplantation. Local graft irradiation was in routine practice for some time for prevention and treatment of refractory acute rejection, but with the availability of better alternatives, TLI has fallen out of favor. 


\section{Calcineurin Inhibitors}

\section{Cyclosporine and Tacrolimus}

$>$ The term calcineurin inhibitors is useful because it emphasizes the similarity in the mechanism of action of the two drugs, cyclosporine and tacrolimus, which have served as the backbone of solid-organ transplant immunosuppression for the past 20 years. Although they are biochemically distinct, they are remarkably similar, not only in their mechanism of action, but also in their clinical efficacy and side-effect profile.

Cyclosporine- Cyclosporine is a small cyclic polypeptide of fungal origin. It consists of 11 amino acids and has a molecular weight of 1203. It is neutral and insoluble in water but soluble in organic solvents and lipids. The amino acids at positions 11, 1, 2, and 3 form the active immunosuppressive site, and the cyclic structure of the drug is necessary for its immunosuppressive effect.

Tacrolimus - Tacrolimus, still often called by its nickname Eff-Kay from its laboratory designation FK506, is a macrolide antibiotic compound isolated from Streptomyces tsukubaensis.

\section{MECHNISM OF ACTION OF CYCLOSPORINE AND TACRILIMUS}

$>$ In the cytoplasm, cyclosporine binds to its immunophilin, cyclophylin, forming a complex between cyclosporine and $\mathrm{CpN}$.

$>$ The cyclosporine-CpN complex binds and blocks the function of the enzyme calcineurin which has a serine/threonine phosphates activity. As a result, CaN fails to dephosphorylate the cytoplasmic component of the nuclear factor of activated T cells (NF-ATc), and thereby the transport of NF-ATc to the nucleus and the binding of NF-ATc to the nuclear component of the nuclear factor of activated T cells (NF-ATn).

$>$ The NF-ATc-NF-ATn complex binds to the promoter of the interleukin 2 (IL-2) gene and initiates IL-2 production. Consequently, T cells do not produce IL-2, which is necessary for full T-cell activation.

$>$ Tacrolimus (FK506) binds to FK506-binding protein (FKBP), forming a FK506-FKBP complex, which binds to and blocks CaN. The FK506-FKBP-CaN complex inhibits the activation of NF-ATc

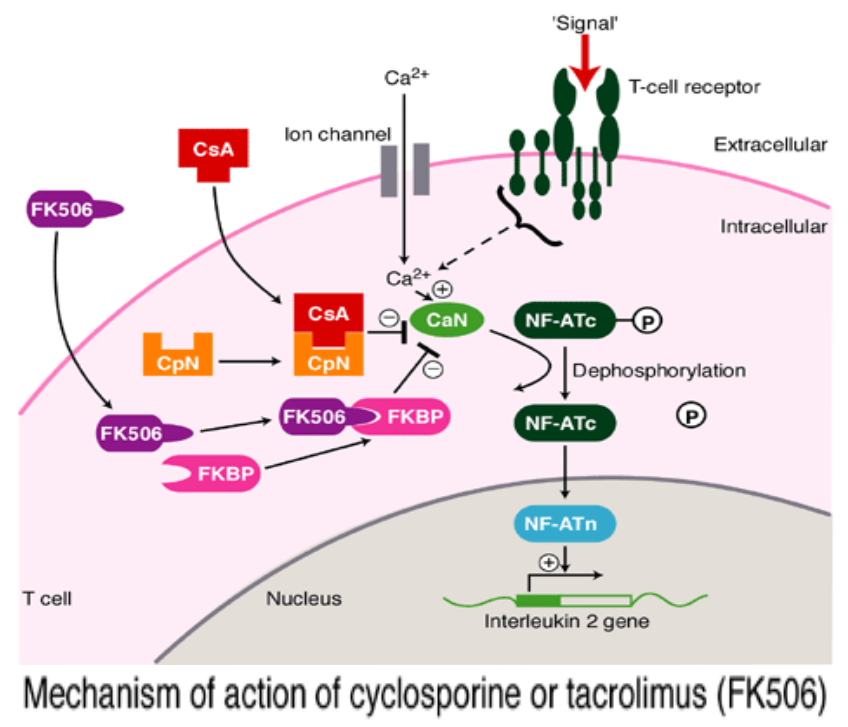

METABOLISM AND DISTRIBUTION-

1. In the blood, one third of absorbed and infused cyclosporine is found in plasma, bound primarily to lipoproteins. Most of the remaining drug is bound to erythrocytes. Whole-blood drug levels (see "Drug Level Monitoring," below) are thus typically threefold higher than plasma levels.

2. Both parent drugs have a half-life of about 8 hours and are metabolized to multiple metabolites by the cytochrome P-450 IIIA (CYP3A) found in the GI and liver microsomal enzyme systems.

3. The liver is often considered the most important site of drug metabolism, but GI metabolism may account for up to half of cyclosporine metabolism.

4. Gut metabolism of Tacrolimus is also extensive. Some of the drug metabolites may have immunosuppressive and nephrotoxicity potential, and the plasma levels of the most important cyclosporine metabolite, M17, may be similar to that of the parent compound. Because both drugs are excreted in the bile with minimal renal excretion, drug doses do not need to be modified in the presence of kidney dysfunction

\section{FORMULATION AND PHARMACOKINETICS OF} CYCLOSPORINE-

1. The original formulation of cyclosporine, the oil-based Sandimmune, has largely been replaced by the microemulsion formulation, Neoral. Both formulations are available in two forms: a $100-\mathrm{mg} / \mathrm{mL}$ solution that is drawn up by the patient into a graduated syringe and dispensed into orange juice or milk, and 25-mg and 100mg soft-gelatin capsules. Patients usually prefer the convenience of the capsule that is typically administered twice daily.

2. The absorption of cyclosporine after an oral dose can be represented graphically in the form of a concentrationtime curve. The time to peak concentration of Sandimmune cyclosporine (tmax) is variable but averages 4 hoursThe bioavailability of Neoral $(F)$ is better than that of Sandimmune, and there is less variability in cyclosporine pharmacokinetics. Peak cyclosporine levels ( $\mathrm{Cmax}$ ) of Neoral cyclosporine are higher, and the trough concentration ( $\mathrm{Cmin}$ ) correlates better with the systemic exposure, as reflected by the area under the curve (AUC).

3. The improved gastrointestinal (GI) absorption of the microemulsion and lesser dependence on bile for absorption may reduce the necessity for intravenous cyclosporine administration. Compared with intravenous infusion, the bioavailability of the orally administered drug is in the range of $30 \%$ to $45 \%$. Conversion between the oral and intravenous forms of the drug perioperatively requires a 3:1 dose ratio. Bioavailability of oral cyclosporine increases with time, possibly as a result of improved absorption by the previously uremic GI tract. As a result, the amount of cyclosporine required to achieve a given blood level tends to fall with time and typically reaches a steady level within 4 to 8 weeks. Food tends to enhance the absorption of cyclosporine. 
International Journal of Trend in Scientific Research and Development (IJTSRD) @ www.ijtsrd.com eISSN: 2456-6470

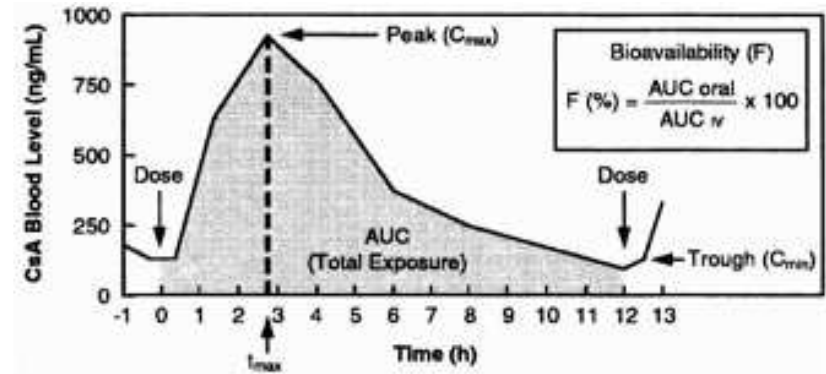

$>$ FORMULTION AND PHARMACOKINETICS OF TACROLIMUS-

- Tacrolimus (Prograf) is available in an intravenous formulation and as 5-mg, 1-mg, and 0.5-mg capsules. It is typically administered twice daily. A long-acting oncedaily formulation (Advagraf) is available in Europe but not in the United states.
- GI absorption is independent of bile salts. Because of the effectiveness and relative consistency of its absorption, it is rarely necessary to use the intravenous formulation, and if necessary, the drug can be administered through a nasogastric tube.

- It is absorbed primarily from the small intestine, and its oral bioavailability is about $25 \%$, with large interpatient and intrapatient variability, particularly for patients with GI disease. Gastric emptying of solids is faster in patients taking tacrolimus than in those receiving cyclosporine, a property that may be beneficial for patients with gastric motility disorders.

- Diarrhea may lead to increased absorption of tacrolimus from the lower GI tract with resultant toxic levels. Generic formulations of tacrolimus are being developed, but as of early 2009, they are not available in the United States. When available, their safety and effectiveness will need to be evaluated with great care.

DRUG INTERACTION WITH CYCLOSPORINE AND TACROLIMUS-

\begin{tabular}{|c|c|c|}
\hline $\begin{array}{l}\text { Increase cyclosporine or } \\
\text { tacrolimus blood levels }\end{array}$ & $\begin{array}{l}\text { Decrease cyclosporine or } \\
\text { tacrolimus blood levels }\end{array}$ & $\begin{array}{l}\text { Increase cyclosporine or } \\
\text { tacrolimus nephrotoxicity }\end{array}$ \\
\hline Ketoconazole & \multirow{4}{*}{$\begin{array}{l}\text { Anticonvulsants: phenytoin, } \\
\text { phenobarbitone, carbamazepine, } \\
\text { others in SClentfflc }\end{array}$} & Amphotericin B \\
\hline Fluconazole & & Amino glycosides \\
\hline Erythromycin & & Cisplatin \\
\hline Diltiazem & & \\
\hline Verapamil & \multirow{2}{*}{ Antibiotics: Rifampicin, rifabutin } & \\
\hline Nicardipine & & \\
\hline Metoclopramide & NSAIDs $J \mid O R \square$ & \\
\hline Methylprednisolone & International.Journal & \\
\hline $\begin{array}{l}\text { Sirolimus } \\
\text { (increases cyclosporine levels) }\end{array}$ & of Trend in Scientific & \\
\hline
\end{tabular}

\section{DRUG LEVEL MONITORING-}

1. Cyclosporine concentrations can be measured in plasma or whole blood. Whole blood (ethylenediaminetetraacetic acid [EDTA] anticoagulated) is the recommended specimen type because the distribution of cyclosporine between plasma and erythrocytes is temperature dependent.

Several methods are currently available to measure cyclosporine, and each differs in specificity for parent compound-

$>$ High-performance liquid chromatography (HPLC) is the most specific method for measuring unmetabolized parent cyclosporine and is considered the reference method.

$>$ Immunoassays, which use monoclonal antibodies against cyclosporine, are commonly used and have largely replaced HPLC because they can be performed on automated chemistry analyzers. The most commonly used immunoassay to measure cyclosporine in whole-blood samples is the Abbott (Chicago, IL) fluorescence polarization immunoassay (FPIA), which has significant cross-reactivity with cyclosporine metabolites and overestimates cyclosporine by as much as $45 \%$.

2. For monitoring of tacrolimus concentrations, most laboratories use the Abbott monoclonal antibody-based microparticle enzyme immunoassay (MEIA) that can be performed on an automated instrument (IMx). This assay permits accurate estimation of tacrolimus levels as low as $2 \mathrm{ng} / \mathrm{mL}$. Abbott has also developed a chemiluminescent microparticle immunoassay (CMIA) that is available on the ARCHITECT family of instruments with a reported detection limit of less than $1 \mathrm{ng} / \mathrm{mL}$. Target cyclosporine (peak and trough) and tacrolimus (trough) levels are discussed in the section on immunosuppressive protocols.

\begin{tabular}{|l|l|l|}
\hline \multicolumn{3}{|c|}{ Comparative features of cyclosporine and tacrolimus } \\
\hline Mode of action & \multicolumn{1}{|c|}{ Cyclosporine } & \multicolumn{1}{c|}{ Tacrolimus } \\
\hline Daily maintenance dose & Inhibition of calcineurin & Inhibition of calcineurin \\
\hline Administration & $3-5 \mathrm{mg} / \mathrm{kg}$ & $0.15-0.3 \mathrm{mg} / \mathrm{kg}$ \\
\hline Absorption bile dependent & and IV & and IV \\
\hline Oral dose available (capsules) & Sandimmune, yes; Neoral, no & No \\
\hline Drug interactions & $100 \mathrm{mg} ; 25 \mathrm{mg}$ & $5 \mathrm{mg} ; 1 \mathrm{mg} ; 0.5 \mathrm{mg}$ \\
\hline Capacity to prevent rejection & Similar & Similar \\
\hline Use with MMF & + & ++ \\
\hline
\end{tabular}


International Journal of Trend in Scientific Research and Development (IJTSRD) @ www.ijtsrd.com eISSN: 2456-6470

\begin{tabular}{|c|c|c|}
\hline Use with sirolimus & $+{ }^{c}$ & $+{ }^{c}$ \\
\hline Nephrotoxicity & + & + \\
\hline Steroid sparing & + & $++?$ \\
\hline Hypertension and sodium retention & ++ & + \\
\hline Pancreatic islet toxicity & + & ++ \\
\hline Neurotoxicity & + & ++ \\
\hline Hirsutism & + & - \\
\hline Hair loss & - & + \\
\hline Gum hypertrophy & + & - \\
\hline Gastrointestinal side effects & - & + \\
\hline Gastric motility & - & + \\
\hline Hyperkalemia & + & + \\
\hline Hypomagnesemia & + & + \\
\hline Hypercholesterolemia & + & - \\
\hline Hyperuricemia/gout & ++ & + \\
\hline \multicolumn{3}{|c|}{$\begin{array}{l}\text { IV rarely needed because oral absorption is good. } \\
\text { b Dose of MMF may be less when used with tacrolimus. } \\
\text { c Nephrotoxicity may be exaggerated when used in full }\end{array}$} \\
\hline
\end{tabular}

SIDE EFFECT OF CYCLOSPORINE THERAPY-

\begin{tabular}{|l|l|}
\hline Renal & Nephrotoxicity,hemolytic-uremic syndrome \\
\hline Hepatic & Hepatotoxicity \\
\hline Neoplastic & Lymphomas, fibroadenoma of breast, squamous cell carcinoma \\
\hline Dermatological & Thickening, rashes, hypertrichosis \\
\hline Gastrointestinal & Anorexia, nausea, failure to gain weight \\
\hline Metabolic & Hyperkalemia, hyperuricemia, hypomagnesemia, hyperglycemia \\
\hline Neurological & Tremor, convulsions, burning sensation in limbs, malaise, depression \\
\hline Cardiovascular & $\begin{array}{l}\text { Fluid retention, hypertension, hypercholesterolemia, Raynaud's } \\
\text { phenomenon, intravascular coagulation }\end{array}$ \\
\hline Dental & Gingival hypertrophy in Scientific \\
\hline Hematological & Hemolytic anemia \\
\hline
\end{tabular}

\section{SYNDROME OF CALCINEURIC INHIBITOR NEPHROTOXICITY-}

$>$ Exaggeration of early post transplantation graft dysfunction

$>$ Acute reversible decrease in Glomerular filtration

$>$ Acute micro vascular disease

$>$ Chronic non-progressive decrease in Glomerular filtration

$>$ Chronic progressive decrease in GFR

$>$ Hypertension and electrolyte abnormalities

$>$ Sodium retention and edema

$>$ Hyperkalemia

$>$ Hypomagnesaemia

$>$ Hyperchloremic acidosis

$>$ Hyperuricemia

A
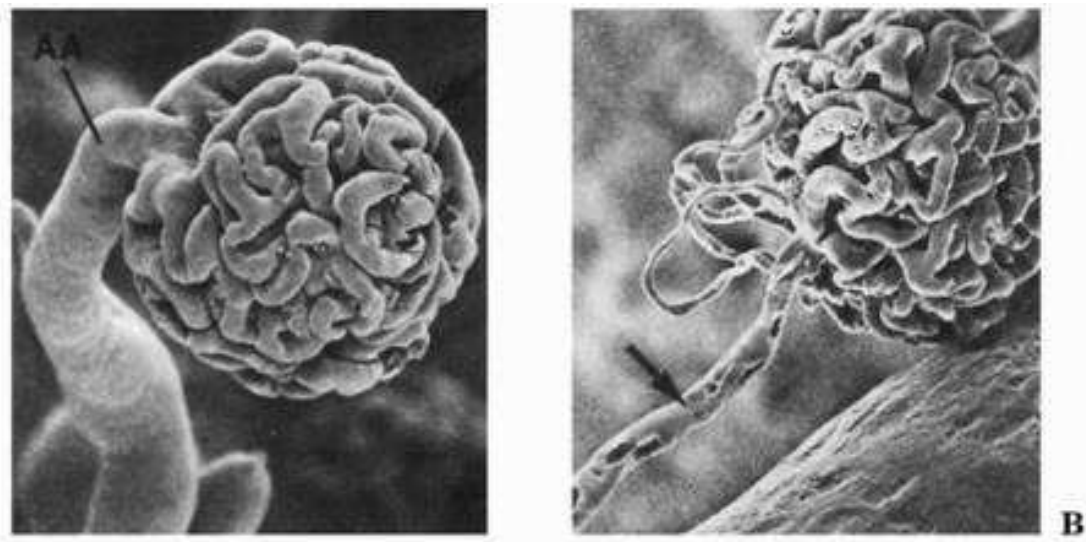

Cyclosporine-induced afferent arteriolar vasoconstriction. A: Control rat showing afferent arteriole (AA) and glomerular tuft. B: Constricted afferent arteriole (arrow) and glomerular tuft after 14 days of cyclosporine at $50 \mathrm{mg} / \mathrm{kg}$ per day. (From English J, Evan A, Houghton DC. Cyclosporine-induced acute renal dysfunction in the rat: evidence of arteriolar vasoconstriction with preservation of tubular function 


\section{METHODS OF AMELIORATION-}

The vexing issue of calcin eurin inhibitor nephrotoxicity has spawned a variety of clinical and experimental approaches designed to modify the renal effects of these drugs, particularly their capacity to produce vasoconstriction. Lowdose dopamine is used in some centers in the early postoperative period to 'encourage' urine output.

Various calcium channel blockers given to both the donor and the recipient may reduce the incidence and severity of delayed graft function.

Omega-3 fatty acids in the form of $6 \mathrm{~g}$ of fish oil each day were initially thought to increase renal blood flow and GFR by reversing the cyclosporine-induced imbalance between the synthesis of vasodilator and vasoconstrictor prostaglandins, but long-term studies have shown no such benefit.

The prostaglandin agonist misoprostol and thromboxane synthetase inhibitors may have a similar effect. (Danowitch GM 2005)

\section{ADVERSE EFFECT ASSOSIATED WITH TACROLIMUS} THERAPY-

\begin{tabular}{|l|l|}
\hline Nephrotoxicity & $\begin{array}{l}\text { Reduced RBF, Glomerular perfusion } \\
\text { Tubular and vascular toxicity } \\
\text { HUS }\end{array}$ \\
\hline Hepatotoxicity & \\
\hline Neurotoxicity & $\begin{array}{l}\text { Tremors, Seizures, Peripheral } \\
\text { neuropathy, Paraesthesias }\end{array}$ \\
\hline $\begin{array}{l}\text { Metabolic } \\
\text { disturbances }\end{array}$ & $\begin{array}{l}\text { Hyperkalemic, hyperchloremic } \\
\text { acidosis, Hypomagnesemia, DM, Trend } \\
\text { Hyperuricemia,Hypercholesterolemia }\end{array}$ \\
\hline Hypertension & $\begin{array}{l}\text { Diarrhea, Anorexia, Nausea, } \\
\text { Vomitting }\end{array}$ \\
\hline $\begin{array}{l}\text { GI } \\
\text { Disturbances }\end{array}$ & $\begin{array}{l}\text { Gingival hypertrophy, gingivitis, } \\
\text { alopecia }\end{array}$ \\
\hline Cosmetic
\end{tabular}

\section{MYCOPHENOLATE MOFETILE}

MMF (CellCept) was introduced into clinical transplantation in 1995 after a series of clinical trials showed that it was more effective than azathioprine for the prevention of acute rejection in recipients of cadaveric kidney transplants when used in combination with cyclosporine and prednisone. MMF is a prodrug, the active compound of which is mycophenolic acid (MPA), a fermentation product of several Penicillium species; the mofetil moiety serves to markedly improve its oral bioavailability. An enteric-coated form of MPA (ERL080, Myfortic) became available in 2004.

Generic formulations of MPA derivatives are available in some parts of the world and became available in the United States in 2009. It is unlikely that the generic formulations will undergo the same risk-benefit evaluation of the brand name drugs. Because therapeutic drug monitoring is not routinely performed during administration of these drugs, it will be difficult to determine their relative clinical effectiveness, and they should be used with caution.

\section{MECHANISM OF ACTION OF MYCOPHENOLATE MOFETILE-}

$>$ MPA is a reversible inhibitor of the enzyme inosine monophosphate dehydrogenase (IMPDH). IMPDH is a critical, rate-limiting enzyme in the so-called de novo synthesis of purines and catalyzes the formation of guanosine nucleotides from inosine. Depletion of guanosine nucleotides by MPA has relatively selective antiproliferative effects on lymphocytes; lymphocytes appear to rely on de novo purine synthesis more than other cell types that have a "salvage" pathway for production of guanosine nucleotides from guanine.

$>$ In principle, MPA is a more selective antimetabolite. It differs radically in its mode of action from the calcineurin inhibitors and sirolimus in that it does not affect cytokine production or the more proximal events following antigen recognition. It differs from azathioprine by virtue of its selective effect on lymphocytes. In vitro, MPA blocks the proliferation of T and B cells, inhibits antibody formation, and inhibits the generation of cytotoxic T cells. MPA also down-regulates the expression of adhesion molecules on lymphocytes, thereby impairing their binding to vascular endothelial cells. The capacity of MMF to treat ongoing rejection may be a reflection of its ability to inhibit the recruitment of mononuclear cells into rejection sites and the subsequent interaction of these cells with target cells.

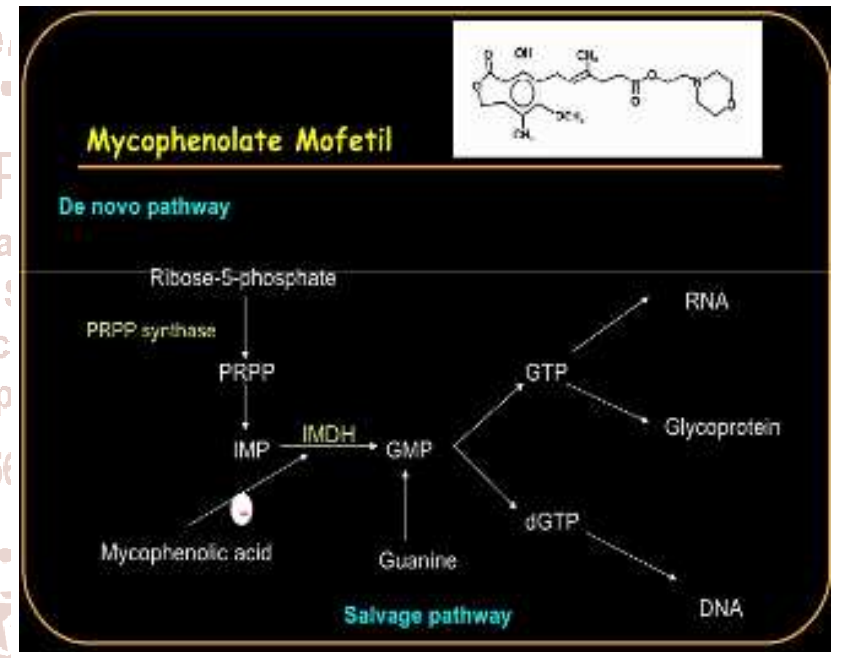

PHARMACHOLOGY OF MYCHOPHENOLATE MOFETILEMMF is a generally well-tolerated and 'user-friendly' compound that is available for clinical use in $250 \mathrm{mg}$ and 500 mg capsules: the standard dose when used with cyclosporine is $1 \mathrm{~g}$ twice daily.

The enteric-coated form is available in $180 \mathrm{mg}$ and $360 \mathrm{mg}$ capsules: the standard dose is $720 \mathrm{mg}$ twice daily. An intravenous preparation is available but is usually not required in kidney transplant recipients. (Danowitch GM 2005) The pharmacokinetics of MMF are complex. Orally administered MMF is rapidly absorbed and hydrolyzed to MPA in the liver, producing a peak level in 1 to 2 hours.

MPA is then glucuronidated to an inactive form (MPAG). Enterohepatic cycling of MPAG can occur producing a second peak occurs at 5 to 6 hours, which may account for some of its GI side effects. Bioavailability of MMF in the capsule form is $90 \%$, with a half-life of 12 hours.

The AUC of MPA is increased by renal impairment, although dose adjustments are not usually made. Neither MMF nor MPA is dialyzed. 


\section{SIDE EFFECT OF MYCOPHENOLATE MOFETILE- Gastrointestinal tract - \\ $>$ Diarrhea \\ $>$ Nausea \\ $>$ Bloating \\ $>$ Dyspepsia \\ $>$ Vomiting. \\ $>$ Esophagitis, gastritis, GI hemorrhage (may be associated with CMV infection). \\ Hematological- \\ $>$ Leucopenia \\ $>$ anemia, \\ $>$ Thrombocytopenia. \\ $>$ Prolonged leukocytosis \\ $>$ Lymphoproliferative disorder.}

\section{DRUG INTERACTION-}

MPA is not metabolized through the CYP3A enzyme system; thus, the multiple drug interactions seen with the calcineurin inhibitors do not occur.

MMF and azathioprine should not be administered concomitantly because of the potential for combined hematologic toxicity.

$>$ Standard hematologic parameters must be carefully followed when MMF is used with sirolimus.

> Cyclosporine lowers MPA concentrations by decreasing its enterohepatic recycling. Trough levels of MPA increase when cyclosporine administration is discontinued.

$>$ This interaction is not seen with tacrolimus or sirolimus and the maintenance dosage of MMF, when used with standard doses and blood levels of these two drugs, is typically $500 \mathrm{mg}$ to $750 \mathrm{mg}$ twice daily.

$>$ MMF should not be administered simultaneously with antacids, cholestyramine or oral ferrous sulfate all of which decrease intestinal absorption.

$>\mathrm{MMF}$, as opposed to azathioprine, can be administered with allopurinol without dose adjustment.

4. m TOR INHIBITOR (mammalian target of rapamycine)

\section{Sirolimus \& Everolimus}

TOR (target of rapamycin) is a key regulatory kinase in the process of cell division. The term 'TOR inhibitor' refers to two similar immunosuppressant drugs whose mode of action is closely linked to inhibition of this kinase. Sirolimus, also known as rapamycin, is a macrolide antibiotic compound that is structurally related to tacrolimus.

Everolimus, also known as RAD, is a similar compound with a shorter half-life. In heart transplant recipients, everolimus is more effective than azathioprine in reducing the severity and incidence of cardiac allograft vasculopathy.

Sirolimus was introduced into clinical transplantation in the United States in 1999. When used in combination with cyclosporine and prednisone, it produced a significant reduction in the incidence of acute rejection episodes in the early post-transplant period.

\section{MECHANISM OF ACTION OF SIROLIMUS}

Although the pre-drug sirolimus (SRL) binds to FK506binding protein (FKBP, which is the same molecule that is bound by FK506), the complex that is formed between SRL and FKBP binds to the mammalian target of rapamycin (mTOR).

The SRL-FKBP-mTOR complex inhibits biochemical pathways that are required for cell progression through the late $G_{1}$ phase or entry into the $S$ phase of the cell cycle.

Thus, unlike cyclosporine (CsA) and FK506 (which block the production of cytokines), SRL blocks cytokine signal transduction.

\section{SRL is thought to target:}

1. the $70-\mathrm{kD}$ S6 protein kinase $\mathrm{p} 70^{\mathrm{s} 6 \mathrm{~K}}$;

2. the eukaryotic initiation factor eIF-4F;

3. the $\mathrm{G}_{1}$-controlling cyclin-dependent kinase (cdk) proteins, such as the D2 cycline cdk2, the D2 cycline cdk6 or the E cycline cdk2 and

4. the kinase inhibitory protein Kip1 (p27kip), which blocks cell progression to the $\mathrm{S}$ phase.

\section{PHARMACOLOGY -}

$1 \mathrm{mg}$ or $2 \mathrm{mg}$ capsule. Sirolimus is rapidly absorbed from the GI tract, reaching peak concentrations in 1 to 2 hours. It has a long half-life, averaging 62 hours, and a steady-state trough concentration can be achieved in most patients within 24 - hours by administering a loading dose three times the size of the maintenance dose.

Everolimus has a half-life of 23 hours and is usually not administered with a loading dose.

Both drugs are largely metabolized by the liver by both CYP3A and p-glycoprotein; the native compound is the major component in human blood and contributes most of the immunosuppressive activity.

Renal excretion is minimal, and dose adjustment is not required in renal dysfunction but is required in hepatic dysfunction.

\section{DRUG INTERACTION-}

The TOR inhibitors and the calcineurin inhibitors are administered together and are metabolized by the same enzyme systems.

In healthy volunteers, concomitant administration of sirolimus and the Neoral formulation of cyclosporine increased the AUC for sirolimus by $230 \%$.

It has been recommended that sirolimus be administered consistently 4 hours after the morning cyclosporine dose.

Sirolimus interacts with calcium channel blockers, antifungal agents, anticonvulsants, and antituberculous agents in a manner similar to the calcineurin inhibitors. Careful surveillance for drug interactions with sirolimus is required. 
ADVERSE EFFECT AND THEIR MANAGEMENT-

\begin{tabular}{|l|l|l|}
\hline \multicolumn{1}{|c|}{ Effect } & \multicolumn{1}{|c|}{ Threshold for action } & \multicolumn{1}{c|}{ Countermeasure therapy } \\
\hline \multirow{3}{*}{ Thrombocytopenia } & $<100000 / \mathrm{mm} 3$ & Dose reduction \\
\cline { 2 - 3 } & $<50000 / \mathrm{mm} 3$ & Drug suspension \\
\cline { 2 - 3 } & $<25000 / \mathrm{mm} 3$ & Oprelvekin $50 \mathrm{mic} / \mathrm{kg} / \mathrm{d}$ \\
\hline \multirow{3}{*}{ Absolute granulocytopenia } & $<2000 / \mathrm{mm} 3$ & Dose reduction \\
\cline { 2 - 3 } & $<1500 / \mathrm{mm} 3$ & Drug suspension \\
\cline { 2 - 3 } Anemia & $<750 / \mathrm{mm} 3$ & Filgrastim $5 \mathrm{mic} / \mathrm{kg} / \mathrm{d}$ \\
\hline \multirow{2}{*}{ Hypertriglyceridemia } & Hematocrit $<32 \%$ & Epoetin alfa 6000 units 3 times $/ / \mathrm{wk}$ \\
\cline { 2 - 3 } & Hematocrit $<25 \%$ & Epoietin 10000 units, 3 times $/$ wk \\
\hline \multirow{2}{*}{ Hypercholesterolemia } & $>300 \mathrm{ng} / \mathrm{dl}$ & Gemfibrozil $600 \mathrm{mg}$ OD \\
\cline { 2 - 3 } & $>500 \mathrm{ng} / \mathrm{dl}$ & Gemfibrozil, fish oil \\
\cline { 2 - 3 } & With hypertriglyceridemia & Pravastatin \\
\cline { 2 - 3 } & Without hypertriglyceridemia & Atorvastatin \\
\hline
\end{tabular}

\section{OTHER ADVERSE EFFECT-}

include diarrhea, hepatotoxicity, impaired healing, pneumonitis, ototoxicity, dermatological effects, pancreatitis, hemolytic anemia, psychotic reactions, torsades de pointes.

\section{Nephrotoxicity}

The TOR inhibitors, when administered alone, do not produce either the acute or chronic reductions in GFR that have been so consistently observed with calcineurin inhibitors. When administered with standard doses of calcineurin inhibitors.

It is recommended that when the drugs are used in combination, the dose of the calcineurin inhibitor should be an attenuated one. The combined TOR inhibitor/calcineurin inhibitor toxicity is reversible.

When cyclosporine is withdrawn from the cyclosporine/sirolimus combination at 3 months posttransplant, there is a consistent and persistent improvement in renal function.

This is manifested not only in lower serum creatinine levels and higher GFR, but in lower uric acid levels and blood pressure, and less marked chronic histologic damage.

The TOR inhibitor may be tubulotoxic and may produce hypokalemia and hypomagnesemia as a result of kaliuresis and magnesuria.

\section{ANTIPROLIFERATIVE AGENT}

$>$ AZATHIOPRINE- The chemical classification of azathioprine is Nucleoside Analog, and Purines. Azathioprine is a purine analogue with cytotoxic and immunosuppressive activity. Azathioprine is aprodrug that is converted by hepatic xanthine oxidase to its active metabolite 6-mercaptopurine (6MP).

- The modern era of pharmacological immunosuppression was initiated by Schwartz and Dameshek in 1959 by documenting that the antiproliferative drug 6-mercaptopurine (6-MP) dampened antibody production and prolonged rabbit skin allograft survival. The imidazole derivative of 6MP, azathioprine, was used by Sir Roy Calne in 1960 demonstrating the prolonged survival of canine renal transplants from 7.5 to 23.7 days .

- Azathioprine is metabolised in liver by thiopurine methyl transferase (TPMT) to 6-MP, the active metabolite, but other pathways also exist and explain individual variation in its metabolism. It interferes with purine metabolism and RNA synthesis, thus inhibiting gene replication and $\mathrm{T}$ cell activation. Individuals with deficiency of TPMT are more sensitive to its myelosuppressive effects .

- The three pivotal trials, the U.S Renal Transplant Study, the TriContinental Study and the European Mycophenolate Mofetil Study compared MMF versus azathioprine or placebo in patients on baseline cyclosporine-prednisolone regimen.

- All trials demonstrated significant reduction in the incidence of acute rejection in MMF group at 6 months (19.8\% vs. $38 \%$; $19.7 \%$ vs. $35.5 \%$; and 17.5 vs. $46.4 \%$, respectively), although graft and patient survivals were not different at 1 year. The cost differential between MMF and azathioprine was 10 fold to 15 fold. An analysis of 49666 primary renal allograft recipients reported to the US renal database system suggested that continued therapy with MMF was associated with protective effect against declining renal function at 1 year compared with azathioprine.

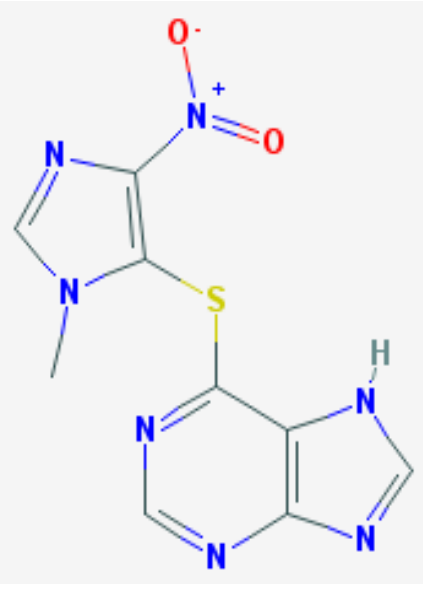

> CYCLOPHOSPHAMIDE- this cytotoxic drug has more marked effect on B cell and humoral immunity compared to that on cell mediate immunity . it is employed only as reserve drug.

\section{MECHNISM OF ACTION OF AZATHIOPRINE}

Azathioprine antagonizes purine metabolism and may inhibit synthesis of DNA, RNA, and proteins. It may also interfere with cellular metabolism and inhibit mitosis. Its mechanism of action is likely due to incorporation of thiopurine analogues into the DNA structure, causing chain termination and cytotoxicity. 
Unlike cyclosporine, it does not prevent gene activation, but it inhibits gene replication and consequent T-cell activation.

Azathioprine is a broad myelocyte suppressant. It inhibits the proliferation of promyelocytes in the bone marrow and, as a result, it decreases the number of circulatory monocytes capable of differentiating into macrophages.

Thus, it is a powerful inhibitor of the primary immune response and is valuable in preventing the onset of acute rejection. It is ineffective in the therapy of rejection episodes.

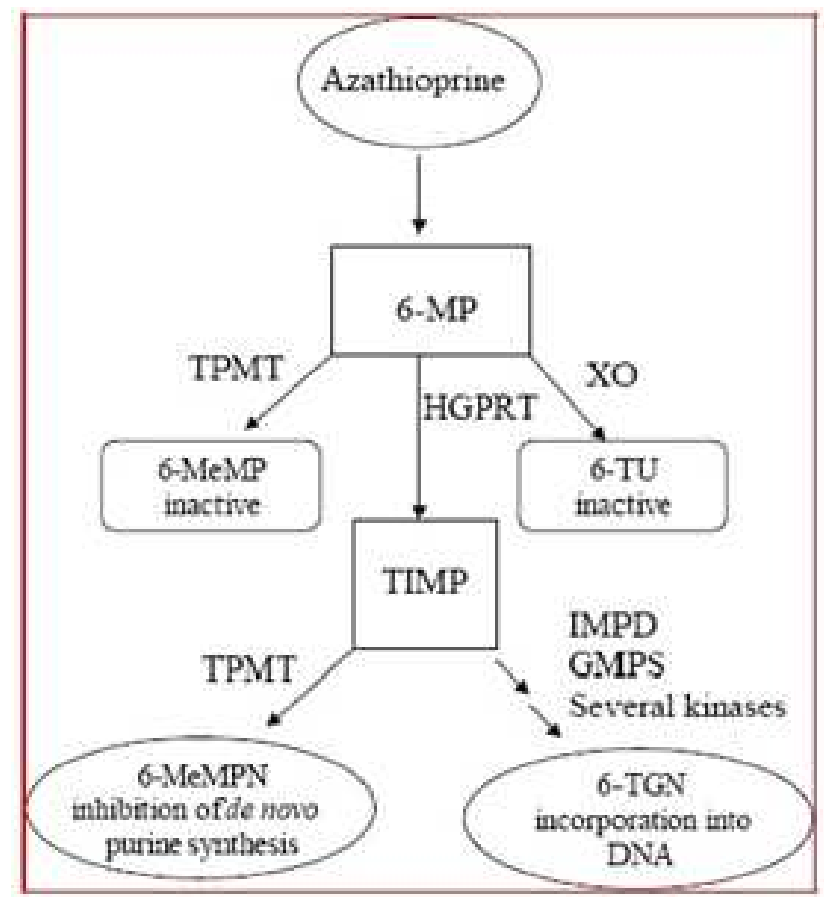

-Azathioprine is metabolized to 6-mercaptopurine (6-MP), which is either inactivated by two enzymes, thiopurine s-methyltranslerase (TPMT) and xanthine oxidase (XO), or is further metabolized to thicinosine monophosphate (TIMP).

- Genetic polymorphism involving the inactivating enzyme TPMT

-Allopurinol inhibits XO, elevate azathioprine bioavailability by fivefold

\section{SIDE EFFECT OF AZATHIOPRINE}

The most important side effects of azathioprine are hematologic. Patients first receiving the drug, particularly in higher dosages ( $2 \mathrm{mg} / \mathrm{kg}$ or more), should have complete blood counts performed, including a platelet count, at least weekly during the first month of therapy, and less frequently thereafter Delayed hematologic suppression may occur.

In the event of significant thrombocytopenia or leukopenia, the drug can be discontinued for long periods if the patient is also taking cyclosporine, without great danger of inducing acute rejection.

Azathioprine may occasionally cause hepatitis and cholestasis, which usually present as reversible elevations in transaminase and bilirubin levels.

\section{DOSE AND ADMINISTRATION-}

$3-5 \mathrm{mg} / \mathrm{kg} /$ day IV/PO initially on day of transplant or 3 days before transplant

Maintenance: $1-3 \mathrm{mg} / \mathrm{kg} /$ day IV/PO.

The drug is not significantly dialyzed or excreted by the kidney. Dose reduction is often practiced during kidney dysfunction, although it may not be necess

\section{CORTICOSTEROID}

Steroid was a pioneering ISA for the first cohort of kidney transplant recipients (KTR) in the early 1960s . Its combination with azathioprine (AZA) produced a very modest one-year graft survival rate, barely reaching 40 to $50 \%$. Subsequent introduction of calcineurin inhibitors (CNI), mycophenolate mofetil (MMF), rapamycin (RAP) and lymphocyte depleting agents led to one-year graft survival rate in excess of $90 \%$. This extra-ordinary feat was, in part, due to the vast improvement in both surgical and organ preservation technologies. However in the last two decades, the steady increase in life span of renal transplant has been driven principally by the attrition rate in the first year. Due to inadequate immunosuppression and/or drug-induced nephrotoxicity, long-term allograft survival has been less satisfactory [4]. Thus rate of deceased donor graft loss in the first year dropped from $20 \%$ in 1989 to $7 \%$ in 2008 , but it remained steadily constant at $5-7 \%$ over the same period for those that survived beyond one year.

\section{MECHANISM OF ACTION}

$>$ Corticosteroids exert their most critical immunosuppressive effect by blocking T-cell-derived and antigen-presenting cell-derived cytokine and cytokine-receptor expression.

$>$ They inhibit the function of dendritic cells. They are hydrophobic and can diffuse intracellularly, where they bind to cytoplasmic receptors found in association with the $90-\mathrm{kDa}$ heat shock protein.

As a result, the heat shock protein becomes dissociated, and the steroid-receptor complex translocates to the nucleus, where it binds to DNA sequences referred to as glucocorticoid response elements (GREs).

$>$ GRE sequences have been found in the critical promoter regions of several cytokine genes, and it is presumed that the binding of the steroid-receptor complex to the GRE inhibits the transcription of cytokine genes.

> Corticosteroids also inhibit the translocation to the nucleus of nuclear factor-Î̃o $\mathrm{B}$, a transcription factor that plays a major role in the induction of genes encoding a wide variety of cytokines.

Corticosteroids inhibit the expression of IL-1, IL-2, IL-3, and IL-6, TNF-al pha, and gamma-interferon. As a result, all stages of the T-cell activation process are inhibited. Cytokine release is responsible for the fever often associated with acute rejection. This fever typically resolves rapidly when high-dose corticosteroids are administered.

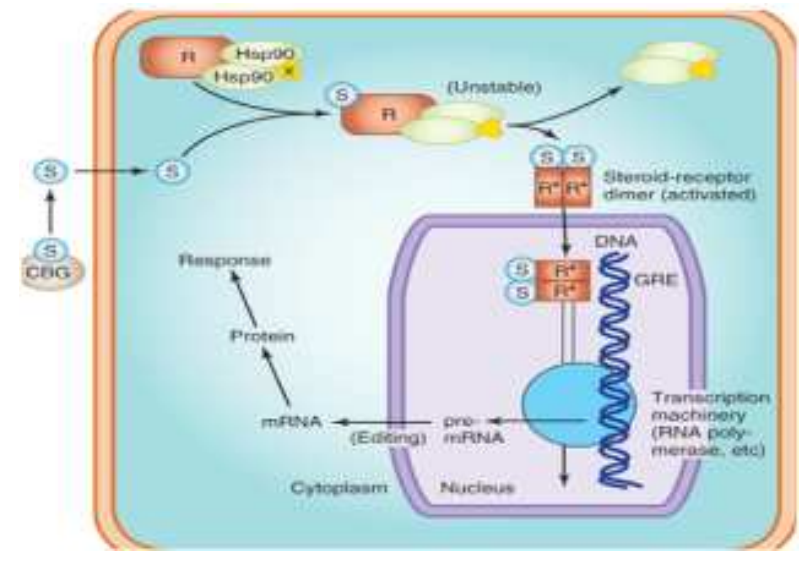

\section{ADVERSE EFFECT-}

these are extensions of the pharmacological action occurring with prolonged therapy. 


\section{A. MINOR ALOCORTICOIDES-}

sodium and water retention, edema, hypokalaemic alkalosis and a progressive rise in BP. These are now rare because of availability of highly selective glucocorticoides.

\section{B. GLUCOCORTICOIDES -}

1. Fragile skin, purple striae- typically on thigh and lower abdomen.

2. Hyperglycaemia, may be glycosuria .

3. Muscular weakness proximal (shoulder, arm, pelvis , thigh) myopathy occurs occasionally- withdraw corticoids .

4. Susceptibility to infection.

5. Delayed healing of wounds and surgical incision.

6. Peptic ulcer.

7. Osteoporosis-specially involving the vertebrae and spongy bones.

8. Posterior subcapsular cataract developed after several yaer of use.

9. Glaucoma.

10. Suppression of hypothalamo-pitutary adrenal axis occurs depending both on dose and duration of therapy.

If a patient on steroid therapy develops an infection - the steroid should not be discontinued despite its propensity to weaken host defence. Rather, the dose may have to be increased to meet the stress of infection.

Measure that minimize the HPA suppression are-

$>$ Use shorter acting steroids at the lowest possible dose.

$>$ Use steroids for shorter duration of time.

$>$ Give an entire daily dose at one time in the morning.

$>$ Switch to alternate day therapy if possible.

COMMONLY USED PREPRATIONS- In transplantation, steroids are used in three ways:

1. High-dose intravenous or oral pulse given over 3 to 5 days;

2. Steroid cycle or taper with a gradually decreasing oral dose over days or weeks;

3. Steady low-dose daily or every-other-day maintenance regimen.

\section{$>$ Prednisolone-}

it is 4 times more potent than hydrocortisone, also more selective glucocorticoids but fluid retention does occurs with high dose . has intermediate duration of action , cause less pituitary - adrenal suppression when a singal morning dose or alternate day treatment is given .its 11-keto metabolite prednisone, and methylprednisolone are the corticosteroid preparations most commonly used in clinical transplantation. Prednisolone is the most active circulating immunosuppressive corticosteroid. Prednisone is the oral preparation usually used.

\section{$>$ Methylprednisolone-}

slightly more potent and more selective than prednisolone 4$32 \mathrm{mg} /$ day oral. It is the most commonly used intravenous corticosteroid. Once-daily administration is adequate.

\section{$>$ METABOLISM-}

Corticosteroids are metabolized by hepatic microsomal enzyme systems.

Drugs such as phenytoin, barbiturates, and rifampin, which induce these enzymes, may lower plasma prednisolone levels, whereas oral contraceptives and ketoconazole increase levels.

\section{DOSE-}

$>$ Methylprednisolone is typically given intraoperatively in a dose of up to $1 \mathrm{~g}$. The dose is then reduced rapidly from $150 \mathrm{mg}$ on day 1 to 20 to $30 \mathrm{mg}$ on day 14 .

$>$ Some programs avoid the steroid cycle altogether, modifying it or starting at $30 \mathrm{mg}$ daily or even less. The maximal oral dose of prednisone at 1 month should be $20 \mathrm{mg}$ and $15 \mathrm{mg}$ at 3 months.

$>$ After a year, many patients tolerate an every-other-day regimen. The low long-term maintenance doses that patients typically receive ( 5 to $7.5 \mathrm{mg}$ daily) should be regarded with great care and respect.

1. Rejection (AR). Such approach will result in overreliance on lymphocyte depleting antibodies and thereby expose patients to avoidable side effects. For this reason, most patients with AR are often treated with pulse doses of steroids.

2. Steroid avoidance is defined as discontinuation of glucocorticoids (GC) within 7 days of transplant surgery. Duration of steroid treatment for less than 3 days produces more frequent delayed graft function .

3. Steroid withdrawal: Early withdrawal refers to discontinuation of steroids use between 7 and 14 days. Late withdrawals are achieved at various time

\section{MONOCLONAL AND POLYCLONAL ANTIBODIES}

\section{Antibody preparations for renal transplant} immunosuppression

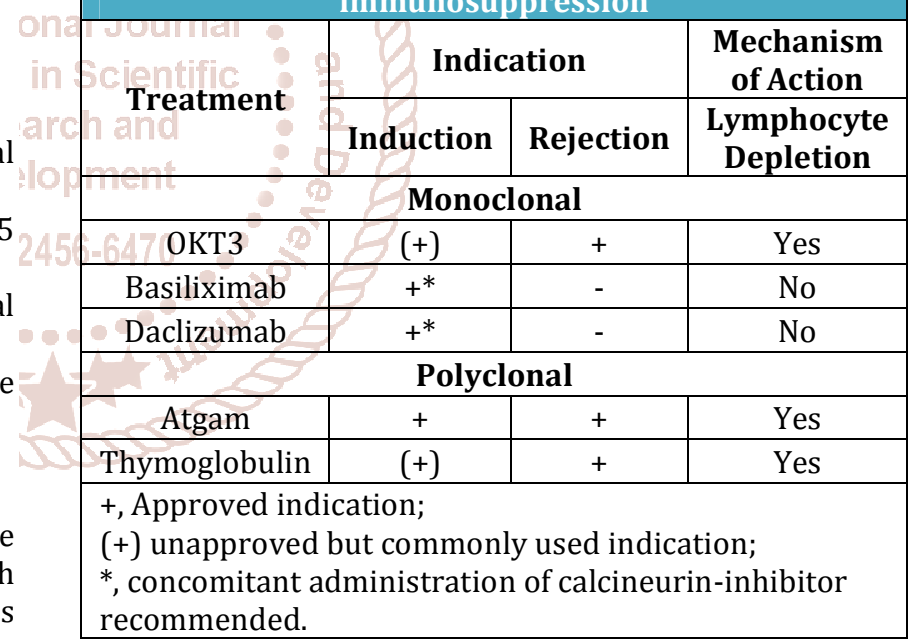

\section{OKT3 (orthoclone)}

\section{MECHANISM OF ACTION-}

OKT3 is a murine monoclonal antibody of the immunoglobulin IgG2a is type. The target of OKT3, CD3, is a 17-20 kilodalton $(\mathrm{kD})$ molecule that is part of a multimolecular complex found only on mature $T$ cells and medullary thymocytes.

This complex is uniquely situated next to the T-cell receptor for antigen. An interaction between T cells, OKT3, and monocytes causes T-cell activation (mitogenesis) in vitro.

Because of the unique association between the antigen receptor and $\mathrm{CD} 3$, antibodies that react with CD3 block T-cell receptor function and vice versa. Thus, OKT3 blocks both the generation and function of cytotoxic T cells. After an initial dose of OKT3, T cells virtually disappear from the circulation within minutes to hours. 
During treatment with OKT3, $\mathrm{T}$ cells bearing the usual array of surface molecules (CD2, CD4, CD8) reappear in the peripheral blood circulation but these cells are devoid of the OKT3 target molecule, CD3. Within 48 hours of discontinuing OKT3, the normal array of surface molecules including CD3 is found again on all $\mathrm{T}$ cells. The selective removal of CD3 by internalization is thought to be the key mechanism of action of OKT3. Comodulation of the antigen receptor with CD3 explains the immunoblocking action of OKT3 in vivo. Experience with a second or third treatment with OKT3 indicates that OKT3 is ineffective clinically if the CD3 target molecule is not modulated. OKT3 has been found to be effective for induction of immunosuppression and for treating initial and steroid-resistan rejections.

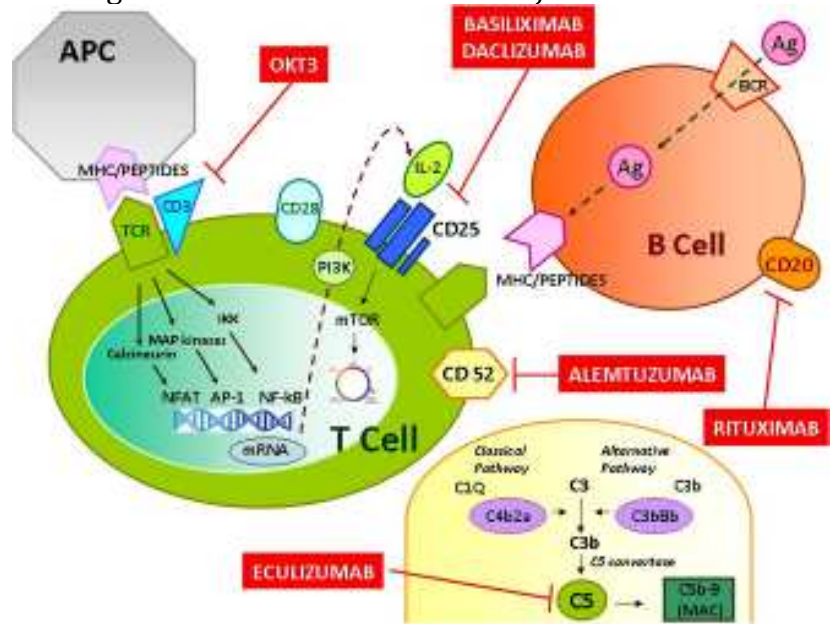

DOSE AND ADMINISTRATION-

The standard dose of OKT3 is $5 \mathrm{mg}$ given as an intravenous bolus through a Millipore filter. The standard course consists of a daily dose for 10 days.

\section{SIDE EFFECT -}

$>$ Chills, febrile reactions

$>$ Nausea, vomiting

$>$ Diarrhea

$>$ Rash,pruritis

$>$ Nephrotoxicity

$>$ Headache, encephalopathy

$>$ Rejection recurrence

$>$ B cell lymphoma.

\section{PROTOCOL RECOMMENDATION FOR OKT3 USE-}

1. Before administration of first dose, patient should be edema free, be within $3 \%$ of dry weight, and have a negative chest radiograph.

2. Use high-dose diuretics, dialysis, or ultrafiltration alone to achieve euvolemiain a volume-overloaded patient.

3. Administer premedication $15-60$ minutes before the first and second doses. The premedication consists of methyl-prednisolone, $5-8 \mathrm{mg} / \mathrm{kg}$; diphenhydramine hydrochloride (Benadryl),50 mg IV; and acetaminophen, $500 \mathrm{mg}$.

4. Before the first and second doses, monitor vital signs every 15 minutes for 2 hours, then every 30 minutes for 2 hours.

5. 5. Premedication is not required for remainder of the course; use acetaminophenp for fever.

6. . If OKT3 is stopped for more than one dose, repeat firstdoseprecautions.

7. Continue low dose of calcineurin-inhibitor, azathioprine, or MMF during thecourse.
8. If calcineurin-inhibitor is continued, use half dose; return to full dose 2 daysbefore completion of the course and ensure therapeutic levels.

9. After the first two doses, continue prednisone according to the protocolschedule.

10. Use antiviral and antibacterial prophylaxis .

11. During second course of OKT3, monitor CD3 levels at least twice weekly.

12. After the first two doses, encourage hydration for patient diuresis.

13. Consider outpatient administration after third dose in stable patients.

\section{Humanized Anti-CD25 Monoclonal Antibodies Mechanism of Action}

$>$ The anti-CD25 monoclonal antibodies basiliximab and daclizu-mab are targeted against the $\hat{I} \pm$ chain (also referred to as CD25, or Tac) of the IL-2 receptor. As a result of the binding of the antibody, IL-2-mediated responses are blocked.

$>$ The anti-CD25 monoclonal antibodies thus complement the effect of the calcineurin inhibitors, which reduce the production of IL-2. They are designed to prevent, but not treat, episodes of acute rejection.

$>$ Basiliximab and daclizumab are two similar compounds that were introduced into clinical transplantation by virtue of their capacity to reduce the incidence of acute rejection episodes when used in combination with cyclosporine and corticosteroids.

$>$ They both originate as murine monoclonal antibodies, which are then genetically engineered so that large parts of the molecule are replaced by human IgG.

i The resulting compounds have low immunogenicity because they do not induce production of significant amounts of human anti-murine antibody.

$>$ As a result, they have a prolonged half-life in the peripheral blood, and they do not induce a first-dose reaction.

$>$ The compounds thus differ from the fully xenogeneic OKT3, which has a short half-life, generates a strong anti-murine response, and has a pronounced first-dose reaction.

\section{Dosage and Administration}

$>$ Basiliximab - two intravenous doses of $20 \mathrm{mg}$ are given, the first dose preoperatively and the second dose on postoperative day 4; this regimen produces saturation of the IL-2̂ิ \pm receptor sites for 30 to 45 days.

> Daclizumab - five doses of $1 \mathrm{mg} / \mathrm{kg}$ are given, starting preoperatively and then at 2-week intervals, producing saturation of the IL-2 sites for up to 12 weeks. Two-dose courses of daclizumab have also been used effectively.

$>$ Side Effects- Both drugs are remarkable by virtue of the absence of significant side effects. Anaphylaxis or firstdose reactions are essentially absent with daclizumab but have occasionally been described with basiliximab

\section{CONCLUSION-}

Renal transplantation is now regarded as a successful and routine procedure. Kidney transplantation has achieved remarkable success over the last century, both technically and scientifically. Sophisticated immunosuprression protocols are now available for the vast majority of patients, rendering hyperacute rejection nearly obsolete, with remarkable improvements in rates of early T-cell-mediated rejection as well. Antimicrobial prophylaxis has advanced 
dramatically. The economic advantages of kidney transplantation over dialysis are more evident than ever, with transplantation costs falling and dialysis costs continuing to increase. However, long-term graft survival remains suboptimal, due largely to inadequate control of the antibody response. Infection and cancer also remain as depressing clinical endpoints for some kidney recipients, and unacceptable rates of death-with-a-functioning-graft persist.

\section{REFRENCES-}

[1] Shrestha A, Shrestha A, Basarab-Horwath C, McKane W, Shrestha B, et al. (2010) Quality of life following live donor renal transplantation: a single centre experience. Ann Transplant 15(2): 5-10.

[2] Merrill JP, Murray JE, Harrison JH, Guild WR (1984) Landmark article Jan 28, 1956: Successful homotransplantation of the human kidney between identical twins. JAMA 251(19): 2566-2571.

[3] Kidney Transplant Activity in 2013 in 104 Countries. World Health Organisation.

[4] Halloran PF (2004) Immunosuppressive drugs for kidney transplantation. N Engl J Med 351(26): 27152729.

[5] Stegall MD, Gaston RS, Cosio FG, Matas A (2015) Through a glass darkly: seeking clarity in preventing late kidney transplant failure. J Am Soc Nephrol 26(1): 20-29.

[6] Medawar PB (1944) The behaviour and fate of skin autografts and skin homografts in rabbits: A report to the War Wounds Committee of the Medical Research Council. J Anat 78(Pt 5): 176-199.

[7] Medawar PB (1945) A second study of the behaviour and fate of skin homografts in rabbits: A Report to the War Wounds Committee of the Medical Research Council. J Anat 79(Pt 4): 157-176.

[8] Kohler G, Hengartner H, Shulman M (1978) Immunoglobulin production by lymphocyte hybridomas. Eur J Immunol 8(2): 82-88.

[9] Kissmeyer-Nielsen F, Olsen S, Petersen VP, Fjeldborg 0 (1966) Hyperacute rejection of kidney allografts, associated with pre-existing humoral antibodies against donor cells. Lancet 2(7465): 662-665.

[10] He H, Stone JR, Perkins DL (2003) Analysis of differential immune responses induced by innate and adaptive immunity following transplantation. Immunology 109(2): 185-196.

[11] Game DS, Lechler RI (2002) Pathways of allorecognition: implications for transplantation tolerance. Transpl Immunol 10(2-3): 101-108.

[12] Vartdal F, Thorsby E (1999) Transplantation immunology--the role of human leucocyte antigen in allorecognition. Curr Top Pathol 92: 1-18.

[13] Ponticelli C (2014) Ischaemia-reperfusion injury: a major protagonist in kidney transplantation. Nephrol Dial Transplant 29(6): 1134[1]. Shrestha A, Shrestha A, Basarab-Horwath C, McKane W, Shrestha B, et al. (2010) Quality of life following live donor renal transplantation: a single centre experience. Ann Transplant 15(2): 5-10.

[14] Sim GK, Yague J, Nelson J, Marrack P, Palmer E, et al. (1984) Primary structure of human T-cell receptor alpha-chain. Nature 312(5996): 771-775.

[15] Snanoudj R, Zuber J, Legendre C (2010) Co-stimulation blockade as a new strategy in kidney transplantation: benefits and limits. Drugs 70(16): 2121-2131.

[16] Poirier N, Blancho G, Vanhove B (2010) Alternatives to calcineurininhibition in renal transplantation: belatacept, the first co-stimulation blocker. Immunotherapy 2(5): 625-636.

[17] Strehlau J, Pavlakis M, Lipman M, Maslinski W, Shapiro $M$, et al. (1996) The intragraft gene activation of markers reflecting T-cell-activation and cytotoxicityanalyzed by quantitative RT-PCR in renal transplantation. Clin Nephrol 46(1): 30-33.

[18] Huang GN, Huso DL, Bouyain S, Tu J, McCorkell KA, et al. (2008) NFAT binding and regulation of $\mathrm{T}$ cell activation by the cytoplasmic scaffolding Homer proteins. Science 319(5862): 476-481. 